\title{
Intracerebroventricular Endothelin Receptor-A Blockade in Rats Decreases Phase-II Ventricular Tachyarrhythmias During Acute Myocardial Infarction
}

\author{
P. LEKKAS ${ }^{1,2}$, E. S. GEORGIOU ${ }^{1}$, M. KONTONIKA ${ }^{1}$, E.-T. MOUCHTOURI ${ }^{1,2}$, \\ I. MOUROUZIS ${ }^{3}$, C. PANTOS ${ }^{3}$, T. M. KOLETTIS ${ }^{1,2}$ \\ ${ }^{1}$ Cardiovascular Research Institute, University of Ioannina, Ioannina, Greece, ${ }^{2}$ Department of \\ Cardiology, Medical School, University of Ioannina, Ioannina, Greece, ${ }^{3}$ Department of \\ Pharmacology, Medical School, National and Kapodistrian University of Athens, Athens, Greece
}

Received February 4, 2019

Accepted May 7, 2019

Epub Ahead of Print August 19, 2019

\begin{abstract}
Summary
Endothelin alters central sympathetic responses, but the resultant effects on arrhythmogenesis are unknown. We examined ventricular tachyarrhythmias after endothelin receptor-A blockade in the brain of Wistar rats with acute myocardial infarction. For this aim, BQ-123 $(n=6)$ or phosphate-buffered saline $(n=6)$ were injected intracerebroventricularly. After $10 \mathrm{~min}$, the left coronary artery was ligated, followed by implantation of telemetry transmitters. Electrocardiography and voluntary activity (as a surrogate of acute left ventricular failure) were continuously monitored for $24 \mathrm{~h}$. Infarct-size was similar in the two groups. There were fewer episodes of ventricular tachyarrhythmias of shorter average duration in treated rats, leading to markedly shorter total duration $(12.3 \pm 8.9 \mathrm{~s})$, when compared to controls $(546.2 \pm 130.3 \mathrm{~s})$. Voluntary activity increased in treated rats during the last hours of recording, but bradyarrhythmic episodes were comparable between the two groups. Endothelin receptor-A blockade in the brain of rats decreases the incidence of ventricular tachyarrhythmias post-ligation, without affecting bradyarrhythmic episodes. These findings call for further research on the pathophysiologic role of endothelin during acute myocardial infarction.
\end{abstract}

\section{Key words}

Myocardial infarction - Brain - Endothelin • A-receptor • Ventricular tachyarrhythmias

\section{Corresponding author}

T. M. Kolettis, Cardiovascular Research Institute, University of Ioannina, 1 Stavrou Niarxou Avenue, 45500 Ioannina, Greece. Fax: +30(265)1007053. E-mail: theofilos.m.kolettis@gmail.com

Acute myocardial infarction (MI) is often complicated by ventricular tachyarrhythmias (VTs) that occur during the early stage of ischemia, or subsequently, during evolving MI (Kolettis 2013). The latter VTs, referred to as phase-II arrhythmogenesis, have an ominous prognosis not only in the out-of-hospital setting, but also in hospitalized patients (Piccini et al. 2008).

Central sympathetic activation, occurring frequently during acute $\mathrm{MI}$, contributes to the genesis of phase-II VTs (Kolettis 2018). Despite continuing research on this topic, the underlying pathophysiology remains incompletely understood. Endothelin-1 (ET-1) has attracted considerable interest in this regard, with its actions as a mediator of central sympathetic responses reported shortly after its discovery (Ouchi et al. 1989). For instance, intracerebroventricular (i.c.v.) injections of ET-1 in rats were shown to alter heart rate (HR) and plasma catecholamines (Kuwaki et al. 1997). These actions are likely exerted via ETA-receptors, which are abundantly located in central neurons (Mosqueda-Garcia et al. 1993). The present study, performed in the rat-model of acute MI, explored the hypothesis that ETA-receptor blockade in the brain decreases the 
incidence of phase-II VTs.

The experiments were conducted on 12 Wistar rats $(258 \pm 7 \mathrm{~g})$, housed under optimal conditions. The study was approved by the institutional ethics' committee and adheres to the European guidelines on laboratory animal care. The rats were mechanically ventilated at 85 breaths $/ \mathrm{min}$ and anesthetized with $2.5 \%$-sevoflurane, a regimen not affecting autonomic responses (Kurosawa et al. 1989). They were placed on a stereotaxic frame (David Kopf, CA, USA), and $10 \mu \mathrm{l}$ of phosphate-buffered saline (PBS) was slowly $(10 \mathrm{~min})$ injected i.c.v. via a Hamilton-needle, according to previous guides (DeVos and Miller 2013). The following coordinates were used relative to the bregma: $1.08 \mathrm{~mm}$ anteroposteriorly, $\pm 1.9 \mathrm{~mm}$ mediolaterally and $-3.7 \mathrm{~mm}$ dorsoventrally. Based on previous data (Mosqueda-Garcia et al. 1993), the injections contained $10 \mathrm{nmol}$ of (the selective ETA-receptor antagonist) BQ-123 (directly dissolved in
PBS) in the treatment group, with only PBS in controls; $10 \mathrm{~min}$ thereafter, the left coronary artery was permanently ligated midway between its origin and the apex, with the induced MI validated by ST-segment elevation in a 6-lead ECG. After $30 \mathrm{~min}$, telemetrytransmitters (TCA-F40, DSI, MN, USA) were implanted quickly $(<10 \mathrm{~min})$ in survivors. The opioid-analgesic buprenorfine $(0.05 \mathrm{mg} / \mathrm{kg})$ was injected intraperitoneally prior to extubation in both groups, thus eliminating pain as a confounding factor. The protocol, depicted in Fig. 1, (i.c.v. administration, anesthesia, analgesia) ensures the comparability between the two groups. The rats regained consciousness within $3 \mathrm{~min}$ after discontinuation of anesthesia, and were then placed on a receiver (RCA-1020, DSI), capturing the signal continuously for $24 \mathrm{~h}$; this setting enables the assessment in the conscious, unrestrained state.

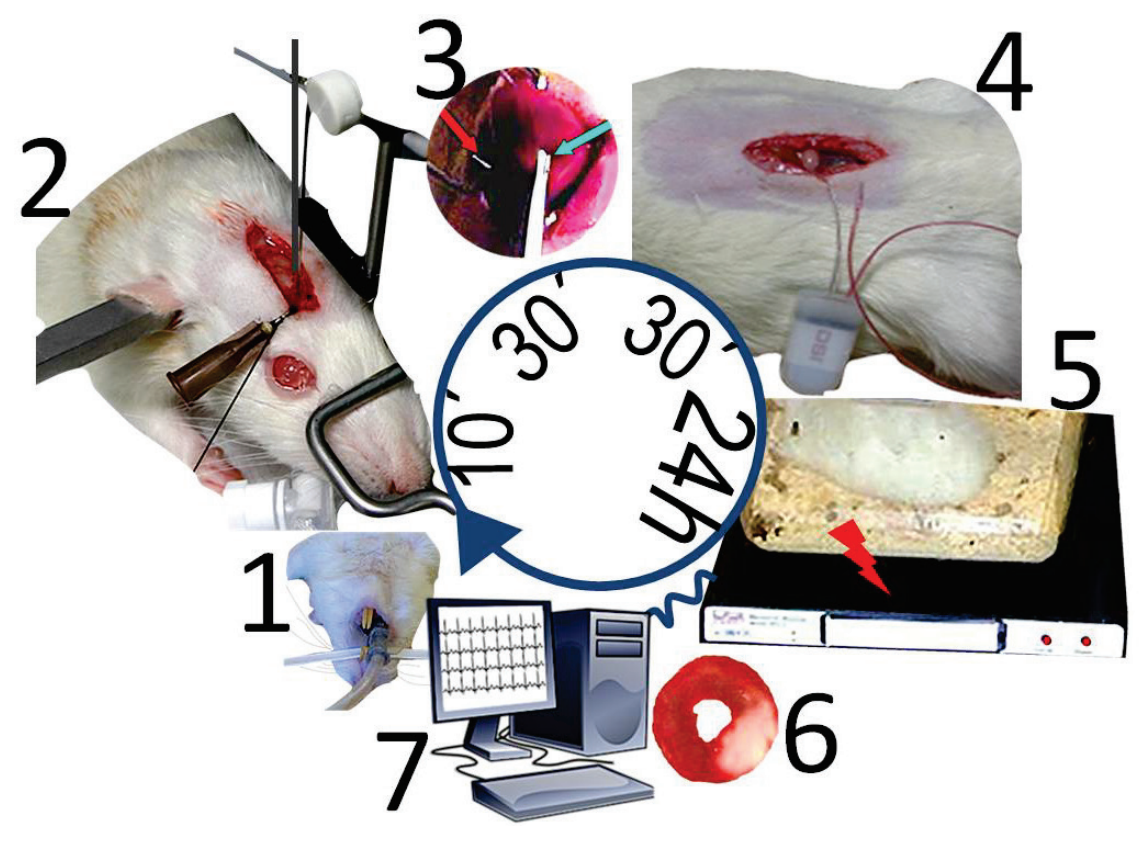

Fig. 1. The study-protocol included, (1) intubation (2) intracerebroventricular injections, (3) induction of myocardial infarction, (4) implantation of telemetry-recorders, (5) $24 \mathrm{~h}$ ECG-recording in conscious animals, (6) measurement of infarct-size, and (7) arrhythmia-analysis.

Premature ventricular contractions, couplets and triplets were counted in the treatment and control groups, each of $n=6$ animals. The number and duration of VT-episodes, as well as bradyarrhythmic events were also recorded. Lastly, voluntary motor-activity was assessed by the number of counts, generated by strengthvariations in telemetry-signal, relative to animal location; these counts correlate with the incidence and severity of acute left ventricular (LV) failure (Howarth et al. 2006). Based on previous work in rats, showing voluntary activity to occur mainly after the $10^{\text {th }}$ hour post-MI (Kolettis et al. 2014), values are given separately for the early (initial $10 \mathrm{~h}$ ) and delayed periods (last $14 \mathrm{~h}$ of recording). Mean sinus HR was calculated separately for these periods and for the entire experiment. At the end, infarct-size was measured by planimetry (ImageJ, NIH, USA) after triphenyltetrazolium-chloride staining, as described previously (Oikonomidis et al. 2010).

Values are reported as mean \pm standard error of the mean; after examination for normality with the Kolmogolov-Smirnov test, the variables displaying skewed distribution were transformed according to BoxCox analysis. Subsequently, differences between the two groups were assessed with the Student's $t$-test, whereas 
changes over time were assessed with analysis of variance for repeated measures, followed by post hoc Duncan's test. Statistical significance was set at $\mathrm{p}<0.05$.

Infarct-size (as \% of LV area) was similar between treated rats $(28.7 \pm 1.9)$ and controls (27.3 \pm 1.6$)$. HR remained stable in controls throughout the 24 h-period, but it increased during the delayed stage in the treatment group (Fig. 2A). The total number of bradyarrhythmic episodes was comparable, namely $52 \pm 23$ in treated rats and $32 \pm 11$ in controls; likewise, the total duration of these episodes did not differ, being $28.8 \pm 12.3 \mathrm{~s}$ and $17.1 \pm 5.6 \mathrm{~s}$, respectively. The total number of premature ventricular contractions was also similar, at $125 \pm 63$ in the treatment group and $207 \pm 52$ in controls, but fewer couplets were observed in the treatment group $(6 \pm 3)$ than in controls $(13 \pm 2)$.

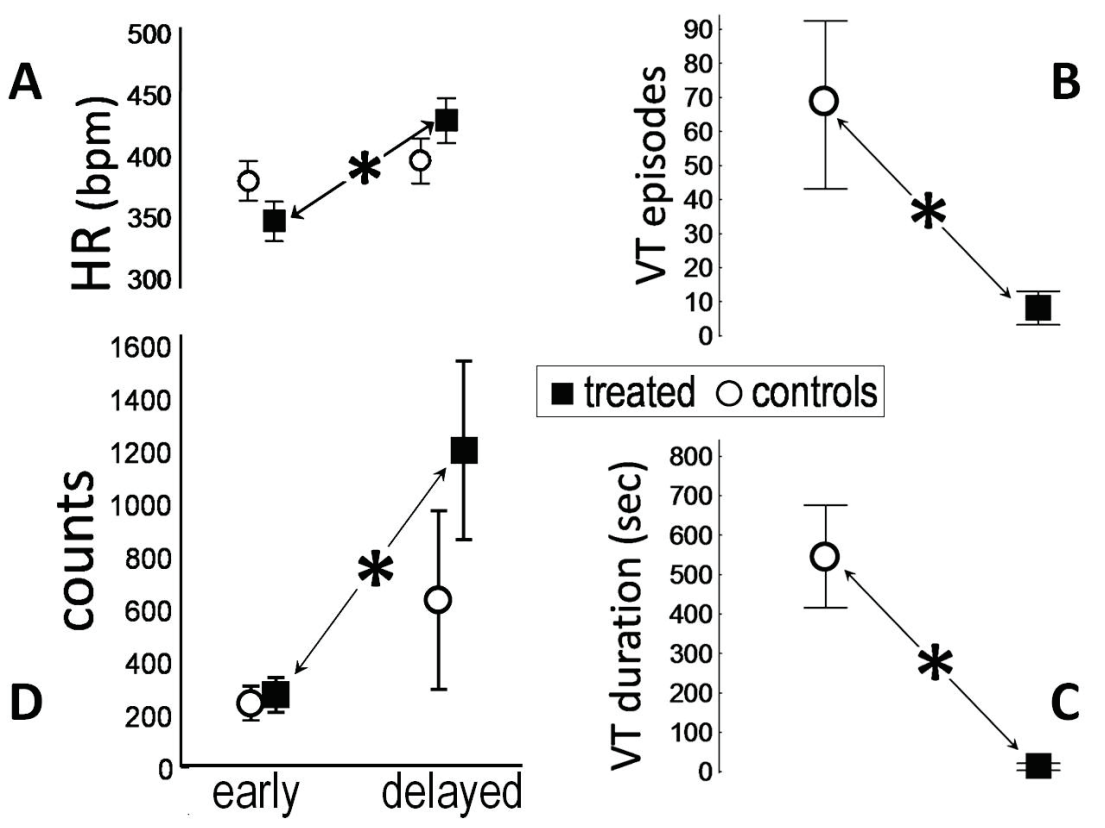

Fig. 2. Heart rate (A) and voluntary activity (B) increased (asterisks, denoting $p=0.0032$ and $p=0.025$, respectively) in treated rats (solid squares) during the delayed period (last $14 \mathrm{~h}$ of the recording), but remained stable in controls (open circles). In treated rats, there were fewer episodes ( $\mathbf{C}, p=0.0058$ ) of ventricular tachyarrhythmias (VTs) of shorter average duration, resulting in lower $(p=0.00075)$ total duration (D).

There were fewer VT-episodes in treated rats ( $8 \pm 5$ ) than in controls ( $68 \pm 25$, Fig. $2 \mathrm{~B})$; moreover, the average duration of each episode was shorter in treated animals $(0.7 \pm 0.4 \mathrm{~s})$ than in controls $(11.3 \pm 3.6 \mathrm{~s})$. As a result, the total duration of VTs was markedly shorter in the treatment group $(12.3 \pm 8.9 \mathrm{~s})$ than in controls (546.2 \pm 130.3 s, Fig. 2C). Compared to the early phase, voluntary activity increased in both groups during the delayed time-period, but such increase was more pronounced in treated rats (Fig. 2D).

Acute MI is often complicated by VTs, with highest incidence during the initial $24 \mathrm{~h}$. Here, we investigated the antiarrhythmic potential of ETA-receptor blockade in the brain of rats; this model is considered particularly useful, as the rat displays multiple VT-episodes in response to coronary ligation (Opitz et al. 1995), thereby maximizing the yield of each experiment. Central ETA-receptor blockade was achieved by i.c.v. injections in the lateral ventricles, with this route favored over systemic administration, based on the absence of firm data on the blood-brain barrier permeability of ETA-receptor blockers. This setting is commonly used in the assessment of compounds with potential central cardiovascular activity, as they can act on many structures after spreading throughout the brain (Dashwood and Loesch 2010). However, its major drawback lies within the inability to accurately identify the responsible nuclei, thus necessitating additional studies. The $24 \mathrm{~h}$-period in our protocol encompassed phase-II arrhythmogenesis, which remains an important therapeutic target, as such VTs coincide with evolving MI and terminate after the completion of the necrosis wavefront (Janse and Wit 1989). As in previous work (Opitz et al. 1995), we observed multiple VT-episodes in the control group, ceasing after the $10^{\text {th }} \mathrm{h}$ post-MI.

The main finding of the present study was the markedly lower incidence of VTs in treated rats. Interestingly, this difference resulted from fewer episodes of shorter duration, supporting the hypothesis of ameliorated central sympathetic activation as the underlying mechanism. Indeed, central sympathetic responses, evident invariably after the $1^{\text {st }} \mathrm{h}$ post-MI (Jardine et al. 2005), are implicated in the genesis of phase-II VTs (Kolettis et al. 2018), mediated by 
enhanced focal automaticity and delayed afterdepolarizations (Di Diego and Antzelevitch 2011). Additionally, sympathetic stimulation shortens the effective refractory period in the non-ischemic zone, which is simultaneously prolonged in the ischemic area (Opthof et al. 1993); these opposite effects may enhance myocardial inhomogeneity, favoring reentry.

The observed antiarrhythmic effect of central ETA-receptor blockade during phase-II is in concert with previous findings, demonstrating ET-1 as an important modulator of sympathetic activity at the myocardial and adrenal levels (Kolettis et al. 2013). Our findings, in the absence of the confounding effects of anesthesia and pain, reinforce previous suggestions on ET-1 as a regulator of central sympathetic responses (Dashwood and Loesch 2010). This intriguing hypothesis merits further investigation that could shed light to the function of ET-1 as a neurotransmitter and/or as a vasoconstrictor of cerebral arteries. Moreover, the pathophysiologic role of ETB-receptors during acute MI deserves particular attention, as these are widely distributed in high density across glial-cells of rats and humans (Morton and Davenport 1992).

Further to VTs, our analysis included bradyarrhythmic episodes, based on previously reported atrioventricular-block, counterbalancing the antiarrhythmic effect of decreased central sympathetic activity (Kolettis et al. 2015). Such episodes reflect not only conduction properties, but they are considered also indicative of acute LV failure in the rat-model (Opitz et al. 1995). In our experiments, bradyarrhythmic episodes did not differ between treated rats and controls, suggesting absence of treatment-effects on atrioventricular-conduction. This finding may reflect enhanced voluntary activity in the treated group, a statement supported by the higher activity counts and HR in this cohort during the delayed post-MI phase. Thus, the effects of central ETA-receptor blockade on the incidence of $\mathrm{LV}$ failure may constitute target for future research.

In summary, our study shows that ETA-receptor blockade in the brain decreases delayed VTs during acute MI in rats, without concurrent bradyarrhythmia. These preliminary findings justify further research on the effects of ET-1 on autonomic responses during acute MI.

\section{Conflict of Interest}

There is no conflict of interest.

\section{References}

CASSINOTTI LR, GUIL MJ, SCHOLLER MI, NAVARRO MP, BIANCIOTTI LG, VATTA MS: Chronic blockade of brain endothelin receptor type-A (ETA) reduces blood pressure and prevents catecholaminergic overactivity in the right olfactory bulb of DOCA-salt hypertensive rats. Int J Mol Sci 19: E660, 2018.

DASHWOOD MR, LOESCH A: Endothelin-1 as a neuropeptide: neurotransmitter or neurovascular effects? $J$ Cell Commun Signal 4: 51-62, 2010.

DEVOS S, MILLER TM: Direct intraventricular delivery of drugs to the rodent central nervous system. $J$ Vis Exp 12: e50326, 2013.

Di DIEGO JM, ANTZELEVITCH C: Ischemic ventricular arrhythmias: experimental models and their clinical relevance. Heart Rhythm 8: 1963-1968, 2011.

HOWARTH FC, JACOBSON M, SHAFIULLAH M, ADEGHATE E: Effects of insulin treatment on heart rhythm, body temperature and physical activity in streptozotocin-induced diabetic rat. Clin Exp Pharmacol Physiol 33: 327-331, 2006.

JANSE MJ, WIT AL: Electrophysiological mechanisms of ventricular arrhythmias resulting from myocardial ischemia and infarction. Physiol Rev 69: 1049-1169, 1989.

JARDINE DL, CHARLES CJ, ASHTON RK, BENNETT SI, WHITEHEAD M, FRAMPTON CM, NICHOLLS MG: Increased cardiac sympathetic nerve activity following acute myocardial infarction in a sheep model. $J$ Physiol 565: 325-333, 2005.

KOLETTIS TM, BARTON M, LANGLEBEN D, MATSUMURA Y: Endothelin in coronary artery disease and myocardial infarction. Cardiol Rev 21: 249-256, 2013.

KOLETTIS TM: Coronary artery disease and ventricular tachyarrhythmia: pathophysiology and treatment. Curr Opin Pharmacol 13: 210-217, 2013. 
KOLETTIS TM, KONTONIKA M, VALENTI MC, VILAETI AD, BALTOGIANNIS GG, PAPALOIS A, KYRIAKIDES ZS: Arrhythmogenesis after acute myocardial necrosis with and without preceding ischemia in rats. J Basic Clin Physiol Pharmacol 25: 143-153, 2014

KOLETTIS TM, KONTONIKA M, BARKA E, DASKALOPOULOS EP, BALTOGIANNIS GG, TOURMOUSOGLOU C, PAPALOIS A, KYRIAKIDES ZS: Central sympathetic activation and arrhythmogenesis during acute myocardial infarction: modulating effects of endothelin-B receptors. Front Cardiovasc Med 2: 6, 2015.

KOLETTIS TM, KONTONIKA M, LEKKAS P, VLAHOS AP, BALTOGIANNIS GG, GATZOULIS KA, CHROUSOS GP: Autonomic responses during acute myocardial infarction in the rat model: implications for arrhythmogenesis. J Basic Clin Physiol Pharmacol 29: 339-345, 2018.

KOLETTIS TM: Autonomic function and ventricular tachyarrhythmias during acute myocardial infarction. World J Exp Med 8: 8-11, 2018.

KUROSAWA M, MEGURO K, NAGAYAMA T, SATO A: Effects of sevoflurane on autonomic nerve activities controlling cardiovascular functions in rats. J Anesth 3: 109-117, 1989.

KUWAKI T, KURIHARA H, CAO WH, KURIHARA Y, UNEKAWA M, YAZAKI Y, KUMADA M: Physiological role of brain endothelin in the central autonomic control: from neuron to knockout mouse. Prog Neurobiol 51: $545-579,1997$

MORTON AJ, DAVENPORT AP: Cerebellar neurons and glia respond differentially to endothelins and sarafotoxin S6b. Brain Res 581: 299-306, 1992.

MOSQUEDA-GARCIA R, INAGAMI T, APPALSAMY M, SUGIURA M, ROBERTSON RM: Endothelin as a neuropeptide. Cardiovascular effects in the brainstem of normotensive rats. Circ Res 72: 20-35, 1993.

OIKONOMIDIS DL, TSALIKAKIS DG, BALTOGIANNIS GG, TZALLAS AT, XOURGIA X, AGELAKI MG, MEGALOU AJ, FOTOPOULOS A, PAPALOIS A, KYRIAKIDES ZS, KOLETTIS TM: Endothelin-B receptors and ventricular arrhythmogenesis in the rat model of acute myocardial infarction. Basic Res Cardiol 105: 235-245, 2010

OPITZ CF, MITCHELL GF, PFEFFER MA, PFEFFER JM: Arrhythmias and death after coronary artery occlusion in the rat. Continuous telemetric ECG monitoring in conscious, untethered rats. Circulation 92: 253-261, 1995.

OPTHOF T, CORONEL R, VERMEULEN JT, VERBERNE HJ, VAN CAPELLE FJ, JANSE MJ: Dispersion of refractoriness in normal and ischaemic canine ventricle: effects of sympathetic stimulation. Cardiovasc Res 27: 1954-1960, 1993.

OUCHI Y, KIM S, SOUZA AC, IIJIMA S, HATTORI A, ORIMO H, YOSHIZUMI M, KURIHARA H, YAZAKI Y: Central effect of endothelin on blood pressure in conscious rats. Am J Physiol 256: H1747-H1751, 1989.

PICCINI JP, BERGER JS, BROWN DL: Early sustained ventricular arrhythmias complicating acute myocardial infarction. Am J Med 121: 797-804, 2008. 